\title{
Erratum to: Reflections on Cultural Preferences and Internal Medicine: The Case of Jehovah's Witnesses and the Changing Thresholds for Blood Transfusions
}

Iftach Sagy $^{1,2} \cdot$ Alan Jotkowitz $^{1} \cdot$ Leonid Barski $^{1}$

\section{Erratum to: J Relig Health}

DOI 10.1007/s10943-016-0353-1

The original version of this article unfortunately contained a mistake in the author name. The co-author name should be Leonid Barski instead of Leonid Barksi.

This has been corrected in the original version of the article.

The online version of the original article can be found under doi:10.1007/s10943-016-0353-1.

Iftach Sagy

iftachsagy@gmail.com

1 Division of Internal Medicine, Soroka University Medical Center, Beer-Sheva, Israel

2 Clinical Research Center, Soroka University Medical Center, 84101 Beer-Sheva, Israel 